\title{
NANOSTRUCTURE FORMATION IN CHIRAL POLY(AMIDE-IMIDE)S BASED ON DOPAMINE MOIETY AND N-TRIMELLITYLIMIDO-L-AMINO ACIDS IN THE MAIN CHAIN
}

\author{
S. MALLAKPOUR ${ }^{* a, b}$, AND A. ZADEHNAZARI ${ }^{a}$ \\ ${ }^{a}$ Organic Polymer Chemistry Research Laboratory, Department of Chemistry, Isfahan University of Technology, Isfahan, 84156-83111, I. R. Iran. \\ ${ }^{b}$ Nanotechnology and Advanced Materials Institute, Isfahan University of Technology, Isfahan, 84156-83111, I. R. Iran
}

(Received: November 25, 2011 - Accepted: April 11, 2012)

\begin{abstract}
Nanostructured poly(amide-imide) (PAI) materials have been produced by polymerizing a diamine monomer, 3,5-diamino-N-(3,4-dihydroxyphenethyl) benzamide, with four trimellitic anhydride-derived, imide ring-preformed chiral amino acid-based dicarboxylic acids. Polycondensation reactions were carried out in the presence of small amount of molten tetrabutylammonium bromide as a green molten salt medium and triphenyl phosphite as the activator by classical heating method. Field emission scanning electron microscopy micrographs showed that the prepared polymers are assembled by spherical particles, which are distributed uniformly and randomly, having nano-sized diameter ranged between 46-54 nm. According to X-ray diffraction patterns, all of PAIs are amorphous. They show excellent solubility in a variety of amide polar solvents and even in less polar solvents such as m-cresol and pyridine. The obtained PAIs were also characterized by Fourier transform infrared spectroscopy, ${ }^{1} \mathrm{H}$ NMR, elemental, and thermogravimetric analysis techniques. The effect of ultrasound on the morphology of polymers was also investigated. This study confirmed that the size of polymer particles was decreased and the shape of them was also changed.
\end{abstract}

Key words: Nanostructure; green chemistry; chiral polymers, polycondensation

\section{INTRODUCTION}

The ability to produce well-ordered arrangements of well-defined and periodic nanostructure materials is critical to the development of high feature density technologies [1,2]. Recently, there has been growing interest in producing materials and products that have dimensions at the micro or nano scale and a great deal of research effort on the subject of nanostructured materials such as nanostructured polymers [3]. Polymers are high molecular weight macromolecules, which leads to a variety of structural features in the condensed phase. They can be 'nanostructured' since they exhibit relevant structural features down at the nanometer length scale. Nanostructured polymers currently gaining great interest because of their wide potential applications in many areas such as biosensors, integrated optics, drug delivery systems, and molecular electronics [4-6]. There are many ways to produce nanostructured polymers including self-assembling method, Langmuir-Blodget technique, layer-by-layer technique, etc. [7-9].

Aromatic polyimides (PI)s as versatile high-performance polymers have been investigated for a variety of applications, for example, aerospace, microelectronics, optoelectronics, nanocomposites, separation membranes, finger-mounted tactile sensors, and for many other applications, because of their excellent balance of thermal, mechanical, and electric insulation properties, and chemical resistance. However, the processing of these thermoplastic polymers has been greatly hindered because they lack softening or melting behaviour at usual processing temperatures and they tend to degrade before or at the softening temperature [10-12]. To overcome these drawbacks, modifications of the PIs structure are often used, for example, introducing kinked and flexible bridging units, nonsymmetrical structures, or bulky substituents into the polymer backbones. In addition, various copolymers have been developed and reported, among them poly (amide-imide)s (PAI)s, whose amide groups can improve the solubility [13]. PAIs have a property between aromatic polyamides and PIs. Thermal stability of PAIs is less than that of PIs but they are processable. High thermal resistance of PAIs is due to heterocyclic imide-ring into polymer chains $[14,15]$. However, they use in a broad range of applications, from injection or compression molded parts and ingots to coatings, films, fibers, membranes, wire enamels, and adhesives [17-19].

In resent years, environmentally-friendly reaction processes have vigorously studied from the standpoint of green chemistry. Most recently, Ionic liquids (IL)s have gained much attention as green reaction solvents for organic synthesis as well as polymerization reactions [19]. ILs are salts, consisting of cations such as imidazolium, pyridinium, quaternary ammonium and quaternary phosphonium, and anions such as halogen, triflate, tetrafluoroborate, and hexafluorophosphate [20]. Molten salts or fused salts are the other names of ILs, as used in older literature. ILs have attracted much attention as safe solvents, due to their low volatility. When a reaction is carried out in an IL as a reaction medium, the solute is solvated by ions only, where the reaction proceeds under different conditions as compared to common organic solvents.
ILs have been utilized for a range of applications such as solvents for organic, catalytic, and polymerization reactions, new material productions, extraction processes, novel electrolytes for electrochemical devices and process, enzyme catalysis/multiphase bioprocess operations, and so on [21-24]. ILs containing quaternary ammonium cation such as molten tetrabutylammonium bromide (TBAB) salt has been investigated for many years. This IL is not only used as reaction solvent, but also exhibit catalytic properties [25-28]. Moreover, TBAB has very high solubility in water and polar organic solvents. Utilization of this property enables recovery and reuse of it, after extracting the product. This can help to reduce the waste of traditional solvents which are rarely reused. In recent times, new applications for molten TBAB as a reaction medium for step growth polymerization have also been presented [29-31].

The development of chiral stationary phases (CSPs) for high-performance liquid chromatography (HPLC) with high recognition ability, wide applicability, and high loading capacity has attracted a lot of attention, and the number of commercially available CSPs has surpassed one hundred. These CSPs for HPLC have been prepared using both chiral small molecules and polymers with chiral recognition abilities [32]. Also polymers with optically active properties have been found interesting application as chiral media for asymmetric synthesis [33]. In the polycondensation reactions we use amino acids as chiral inducting agents. These materials are naturally occurring compounds and synthetic polymers based on amino acids are expected to be biodegradable and biocompatible [34].

This study aims to fabricate new chiral nanostructured PAIs having amino acid in the backbone and dopamine residue in the side chain from 3,5-diamino-N-(3,4-dihydroxyphenethyl)benzamide and various optically active N-trimellitylimido-L-amino acids, by direct step-growth polymerization method in molten TBAB, a cheap commercially available ionic salt. The effect of ultrasonic irradiation on the morphology of polymers would investigate.

\section{EXPERIMENTAL SECTION}

Materials

All chemicals were purchased from Fluka Chemical Co. (Switzerland), Aldrich Chemical Co. (Milwaukee, WI), Riedel-deHaen AG (Germany), and Merck Chemical Co. (Germany). Dopamine hydrochloride (3-hydroxytyraminium chloride), 3,5-dinitrobenzoylchloride, N,N'dimethylacetamide (DMAc), and propylene oxide from Merck were used for the synthesis of mediators. Propylene oxide was used as acid scavenger. $\mathrm{N}, \mathrm{N}^{\prime}-$ dimethylformamide (DMF) $\left(\mathrm{d}=0.94 \mathrm{~g} \mathrm{~cm}^{-3}\right.$ at $\left.20^{\circ} \mathrm{C}\right)$, and DMAc as solvent $\left(\mathrm{d}=0.94 \mathrm{~g} \mathrm{~cm}^{-3}\right.$ at $\left.20^{\circ} \mathrm{C}\right)$ were distilled over barium oxide under reduce pressure. Other reagents were used without further purification.

Techniques

Proton nuclear magnetic resonance $\left({ }^{1} \mathrm{H}\right.$ NMR, $\left.400 \mathrm{MHz}\right)$ spectra were carried out at a Bruker (Germany) Avance 500 instrument at room temperature (RT) in dimethylsulphoxide- $d_{6}\left(\mathrm{DMSO}-d_{6}\right)$. Multiplicities of proton resonance 
were designated as singlet ( $\mathrm{s})$, doublet $(\mathrm{d})$, triplet $(\mathrm{t})$, and multiplet $(\mathrm{m})$. FTIR spectra were recorded on a spectrophotometer (Jasco-680, Japan). The spectra of solids were obtained using $\mathrm{KBr}$ pellets. The vibrational transition frequencies are reported in wavenumbers $\left(\mathrm{cm}^{-1}\right)$. Band intensities are assigned as weak (w), medium (m), strong (s), and broad (br). Inherent viscosities were measured by using a Cannon Fenske Routine Viscometer (Germany) at the concentration of $0.5 \mathrm{~g} / \mathrm{dL}$ at $25^{\circ} \mathrm{C}$. Specific rotations were measured by a Jasco Polarimeter (Japan). Thermal gravimetric analysis (TGA) is performed with a STA503 win TA at a heating rate of $20^{\circ} \mathrm{C} / \mathrm{min}$ from $25^{\circ} \mathrm{C}$ to $800^{\circ} \mathrm{C}$ under nitrogen atmosphere. The XRD diffractograms of polymers were recorded using an XRD (Bruker, D8ADVANCE, Germany) with a copper target at 40 $\mathrm{kV}$ and $35 \mathrm{~mA}$ and $\mathrm{Cu} \mathrm{K \alpha} \lambda=1.54 \AA$ in the range $10-80^{\circ}$ at the speed of $0.05^{\circ} \mathrm{min}^{-1}$. The morphology of the polymers was observed using FE-SEM (HITACHI S-4160). The effect of ultrasonic radiation on the size of polymer particles was investigated by MISONIX ultrasonic liquid processors, XL-2000 SERIES. Ultrasound was a wave of frequency $2.25 \times 10^{4} \mathrm{~Hz}$ and power $100 \mathrm{~W}$.

Monomer synthesis procedure

3,5-diamino-N-(3,4-dihydroxyphenethyl)benzamide (4) as a diamine monomer was prepared according to our published article and is shown in Scheme 1 [35].

Optically active diacid monomers (7a-7d) such as: N-trimellitylimidoL-leucine [36], N-trimellitylimido-L-isoleucine [37], N-trimellitylimido-Svaline [38], and $\mathrm{N}$-trimellitylimido-L-alanine [39] were prepared according to previous works (Scheme 2).

Polymer synthesis procedure

The PAIs were prepared by the following procedure: for the synthesis of PAI8a, A mixture of aromatic diacid $7 \mathrm{a}\left(0.100 \mathrm{~g}, 3.27 \times 10^{-4} \mathrm{~mol}\right)$, diamine 4 $\left(0.091 \mathrm{~g}, 3.27 \times 10^{-4} \mathrm{~mol}\right)$, and TBAB $\left(0.420 \mathrm{~g}, 1.31 \times 10^{-3} \mathrm{~mol}\right)$ was ground until a powder was formed. After the mixture was completely ground, it was transferred into a $25 \mathrm{~mL}$, round-bottom flask and then $0.34 \mathrm{~mL}\left(1.31 \times 10^{-3}\right.$ mol) of triphenyl phosphite (TPP) was added to the mixture which was heated until a homogeneous solution was formed. Then, the solution was stirred for $12 \mathrm{~h}$ at $120^{\circ} \mathrm{C}$, and the viscous solution was precipitated in $15 \mathrm{~mL}$ of methanol. The orange solid was filtered off and dried to give $0.164 \mathrm{~g}(90 \%)$ of PAI8a. The other PAIs, PAI8b-PAI8d were prepared by a similar procedure.

PAI8a: FTIR (KBr, $\left.\mathrm{cm}^{-1}\right): 3,370(\mathrm{~m}, \mathrm{br}, \mathrm{NH}$ and $\mathrm{OH}$ stretching), 3,100 (w, C-H aromatic) 2,958 (m, C-H aliphatic), 2,928 (w, C-H aliphatic), 1,776 ( $\mathrm{m}, \mathrm{C}=\mathrm{O}$ imide, asymmetric stretching), 1,717 ( $\mathrm{s}, \mathrm{C}=\mathrm{O}$ imide, symmetric stretching), 1,648 (m, C=O amide, stertching), 1,599 (m), 1,551 (s), 1,446 (s), 1,378 (s, CNC axial stretching), 1,197 (m, CNC transverse stretching), 1,062 (w), $960(\mathrm{~m}), 864(\mathrm{~m}), 812(\mathrm{~m}), 727$ (s, CNC out-of-plane bending), $683(\mathrm{w})$.

PAI8b: 3,416 (m, br, $\mathrm{NH}$ and $\mathrm{OH}$ stretching), 3,114 (w, C-H aromatic), 2,963 (w, C-H aliphatic), 2,927 (w, C-H aliphatic), 1,776 (m, C=O imide, asymmetric stretching), 1,717 (s, C=O imide, symmetric stretching), 1,647 (m, $\mathrm{C}=\mathrm{O}$ amide, stertching), 1,599 (s), 1,550 (m), 1,446 (s), 1,376 (m, CNC axial stretching), 1,198 (m, CNC transverse stretching), 1,073 (m), $865(\mathrm{~m}), 766(\mathrm{~m})$, 725 (s, CNC out-of-plane bending), 683 (w). 'H NMR (400 MHz, DMSO-d, ppm): 0.91 (t, $3 \mathrm{H}, \mathrm{CH}_{3}$, distorted ), $1.29\left(\mathrm{~d}, 3 \mathrm{H}, \mathrm{CH}_{3}, J=7.20 \mathrm{~Hz}\right), 1.50(\mathrm{~m}$, $\left.2 \mathrm{H}, \mathrm{CH}_{2}\right), 2.59(\mathrm{~m}, 1 \mathrm{H}, \mathrm{CH}), 2.87\left(\mathrm{t}, 2 \mathrm{H}, \mathrm{CH}_{2}\right.$, distorted $), 3.15\left(\mathrm{t}, 2 \mathrm{H}, \mathrm{CH}_{2}\right.$, distorted), $4.63-4.65(\mathrm{~d}, 1 \mathrm{H}, \mathrm{CH}, J=8.40 \mathrm{~Hz}), 6.45-6.47(\mathrm{~d}, 1 \mathrm{H}, \mathrm{Ar}-\mathrm{H}, J=8.40$ $\mathrm{Hz}), 6.61-6.63(\mathrm{~d}, 1 \mathrm{H}, \mathrm{Ar}-\mathrm{H}$, distorted), $7.66(\mathrm{~s}, 1 \mathrm{H}, \mathrm{Ar}-\mathrm{H}), 7.71(\mathrm{~s}, 1 \mathrm{H}, \mathrm{Ar}-\mathrm{H})$, $7.94(\mathrm{~s}, 1 \mathrm{H}, \mathrm{Ar}-\mathrm{H}), 8.00(\mathrm{~s}, 1 \mathrm{H}, \mathrm{Ar}-\mathrm{H}), 8.10$ (d, 1H, Ar-H, distorted), 8.46 (s, $1 \mathrm{H}, \mathrm{Ar}-\mathrm{H}), 8.51-8.53$ (d, $1 \mathrm{H}, \mathrm{Ar}-\mathrm{H}$, distorted), $8.76(\mathrm{~s}, 1 \mathrm{H}, \mathrm{NH}), 10.15(\mathrm{~s}, 1 \mathrm{H}$, $\mathrm{OH}), 10.23(\mathrm{~s}, 1 \mathrm{H}, \mathrm{OH}), 10.78(\mathrm{~s}, 1 \mathrm{H}, \mathrm{NH}), 10.85(\mathrm{~s}, 1 \mathrm{H}, \mathrm{NH})$.

Elemental analysis: calculated for $\left(\mathrm{C}_{30} \mathrm{H}_{28} \mathrm{~N}_{4} \mathrm{O}_{7}\right)_{\mathrm{n}}: \mathrm{C}, 64.74 \% ; \mathrm{H}, 5.07 \% ; \mathrm{N}$, $10.07 \%$. Found: C, $64.35 \% ; \mathrm{H}, 4.96 \% ; \mathrm{N}, 10.29 \%$

PAI8c: FTIR ( $\left.\mathrm{KBr}, \mathrm{cm}^{-1}\right): 3,392(\mathrm{~m}, \mathrm{br}, \mathrm{NH}$ and $\mathrm{OH}$ stretching), 3,101 (w, C-H aromatic), 2,962 (w, C-H aliphatic), 2,930 (w, C-H aliphatic), 1,777 ( $\mathrm{m}, \mathrm{C}=\mathrm{O}$ imide, asymmetric stretching), $1,719(\mathrm{~s}, \mathrm{C}=\mathrm{O}$ imide, symmetric stretching), 1,648 (s, C=O amide, stertching), 1,599 (s), 1,547 (s), 1,445 (s), 1,376 (s, CNC axial stretching), 1,198 ( $\mathrm{m}, \mathrm{CNC}$ transverse stretching), 1,068 (m), $871(\mathrm{~m}), 764(\mathrm{~m}), 726$ (s, CNC out-of-plane bending), 681 (w). ${ }^{1} \mathrm{H}$ NMR (400 MHz, DMSO- $d$, ppm): 0.85 (d, 3H, CH, distorted), 1.30-1.31 (d, 3H, $\left.\mathrm{CH}_{3}, J=5.4 \mathrm{~Hz}\right), 1.56(\mathrm{~m}, 1 \mathrm{H}, \mathrm{CH}), 2.63\left(\mathrm{t}, 2 \mathrm{H}, \mathrm{CH}_{2}\right.$, distorted), $3.16(\mathrm{t}, 2 \mathrm{H}$, $\mathrm{CH}_{2}$, distorted), $4.73(\mathrm{~d}, 1 \mathrm{H}, \mathrm{CH}$, distorted), 6.47-6.49 (d, $1 \mathrm{H}, \mathrm{Ar}-\mathrm{H}, \mathrm{J}=8.40$ $\mathrm{Hz})$, 6.61-6.63 (d, 1H, Ar-H, $J=7.2), 7.67(\mathrm{~s}, 1 \mathrm{H}, \mathrm{Ar}-\mathrm{H}), 7.74(\mathrm{~s}, 1 \mathrm{H}, \mathrm{Ar}-\mathrm{H})$, $7.94(\mathrm{~s}, 1 \mathrm{H}, \mathrm{Ar}-\mathrm{H}), 7.99(\mathrm{~s}, 1 \mathrm{H}, \mathrm{Ar}-\mathrm{H}), 8.08(\mathrm{~d}, 1 \mathrm{H}, \mathrm{Ar}-\mathrm{H}$, distorted), $8.52(\mathrm{~s}$, $1 \mathrm{H}, \mathrm{Ar}-\mathrm{H}), 8.63-8.65(\mathrm{~d}, 1 \mathrm{H}, \mathrm{Ar}-\mathrm{H}$, distorted), $8.75(\mathrm{~s}, 1 \mathrm{H}, \mathrm{NH}), 10.22(\mathrm{~s}, 1 \mathrm{H}$, $\mathrm{OH}), 10.31(\mathrm{~s}, 1 \mathrm{H}, \mathrm{OH}), 10.77(\mathrm{~s}, 1 \mathrm{H}, \mathrm{NH}), 10.84(\mathrm{~s}, 1 \mathrm{H}, \mathrm{NH})$.

Elemental analysis: calculated for $\left(\mathrm{C}_{29} \mathrm{H}_{26} \mathrm{~N}_{4} \mathrm{O}_{7}\right): \mathrm{C}, 64.20 \% ; \mathrm{H}, 4.83 \% ; \mathrm{N}$, $10.33 \%$. Found: $\mathrm{C}, 64.12 \% ; \mathrm{H}, 4.62 \% ; \mathrm{N}, 10.21 \%$.

PAI8d: FTIR $\left(\mathrm{KBr}, \mathrm{cm}^{-1}\right): 3,393(\mathrm{~m}, \mathrm{br}, \mathrm{NH}$ and $\mathrm{OH}$ stretching), 3,100 (w, C-H aromatic), 2,959 (w, C-H aliphatic), 2,926 (w, C-H aliphatic), 1,776 ( $\mathrm{m}, \mathrm{C}=\mathrm{O}$ imide, asymmetric stretching), 1,717 ( $\mathrm{s}, \mathrm{C}=\mathrm{O}$ imide, symmetric stretching), 1,656 (m, C=O amide, stertching), 1,599 (s), 1,552 (m), 1,446 (s), 1,380 (s, CNC axial stretching), 1,199 (m, CNC transverse stretching), 1,065 (m), $870(\mathrm{~m}), 766(\mathrm{~m}), 727$ (s, CNC out-of-plane bending), $693(\mathrm{w})$.

\section{RESUSLTS AND DISCUSSION}

\section{Monomer synthesis}

Diamine monomer 4 was synthesized by using a two-step reaction according to our previous work (Scheme1) [35]. Diacid monomers were synthesized by the condensation reaction of an equimolar amount of trimellitic anhydride (5) and different amino acids [L-leucine, L-isoleucine, S-valine, and L-alanine (6a-6d)] in reflux acetic acid solution, as shown in Scheme 2 [36-39].

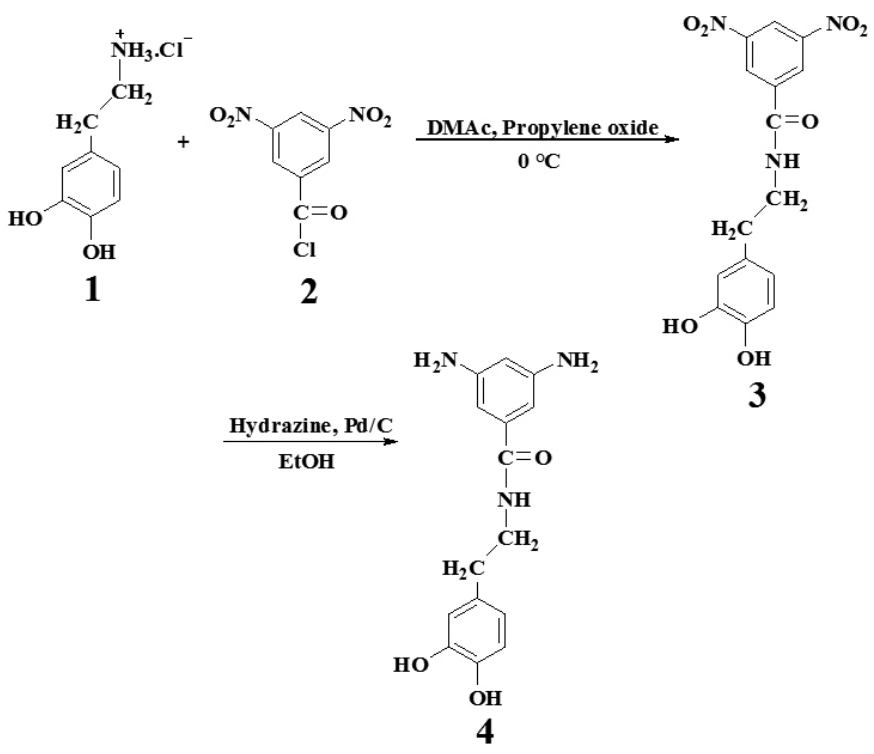

Scheme 1: Synthetic route of diamine 4

\section{Polymer synthesis}

The direct polycondensation of a dicarboxylic acid and diamine in a conventional organic solvent is one of the well-known methods for PAI synthesis. There is a great need to develop new methodologies for manipulation of different functionalities in polymerization reactions using green chemistry that could replace the conventional solvents and provide better conditions. In contrast to common organic solvents, ILs do not produce volatile organic compounds due to their low vapor pressure. Also, ILs are inexpensive to prepare and easy to recycle. So, in this research we tried to eliminate common organic solvents such as N-methyl-2-pyrrolidone (NMP), DMAc, and DMF and performed the polymerization reaction under green conditions to report a simple, safe, and efficient method for synthesis of several optically active PAIs via direct polycondensation reaction of several natural amino acid-based diacids (7a-7d) with an aromatic dopamine-based diamine (4) in molten TBAB in the presence of TPP (Scheme 2). This IL was selected because it proved to be the most valuable among those employed in our recent works [29-31]. Runs in IL were carried out by thermal heating technique. The entire polycondensation reaction readily proceeds in a homogeneous solution and after work up tough and stringy precipitates was formed. The syntheses and some physical properties of these new PAIs ( $8 \mathrm{a}-8 \mathrm{~d}$ ) are given in Table 1 . All the polymers were obtained in high yields (85-92\%), and the inherent viscosities were 0.42 $0.48 \mathrm{dL} / \mathrm{g}$ which were measured in DMF solutions. Also the resulting polymers showed an orange color. All of them are also optically active, because they have a chiral center from amino acid residue in their pendant groups. The structure of the PAIs was confirmed by FTIR and ${ }^{1} \mathrm{H}$ NMR spectroscopy, and elemental analysis technique. 


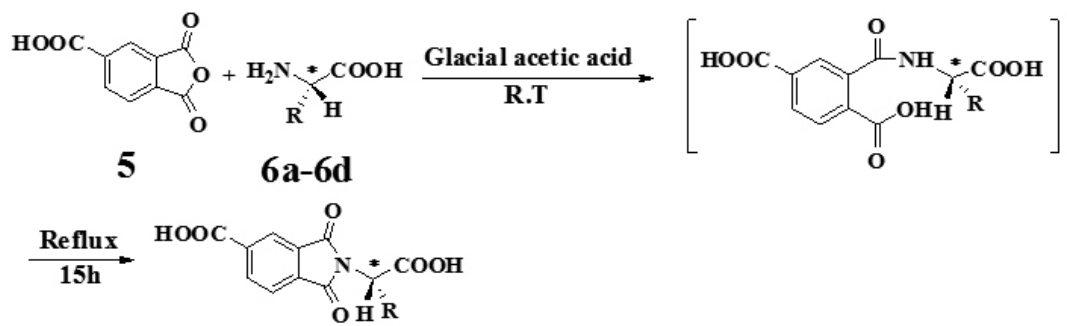

7a-7d

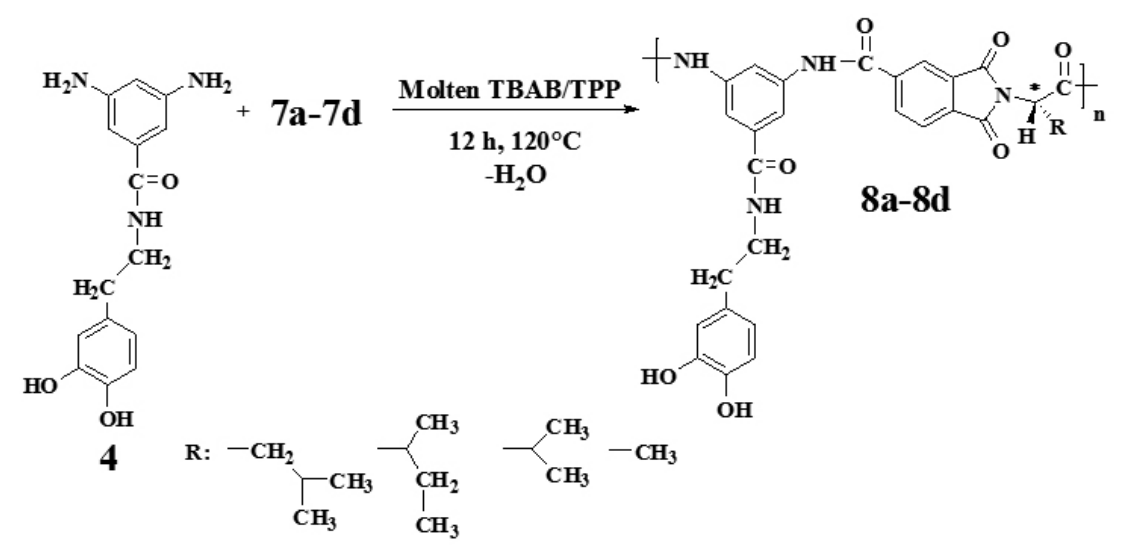

\section{a: Leu b: Ile c: Val d: Ala}

Scheme 2: Synthesis of PAIs 8a-8d

Table 1: Synthesis and some physical properties of PAI8a-PAI8d prepared in molten TBAB.

\begin{tabular}{|c|c|c|c|c|c|c|}
\hline Diacid & Polymer $^{\mathrm{a}}$ & Yield (\%) & $\begin{array}{l}\text { Inherent Viscosity } \\
(\mathrm{dL} / \mathrm{g})\end{array}$ & {$[\alpha]_{\mathbb{N}, 589}^{\mathbb{8}, b}$} & {$[\alpha]_{\mathbb{Z}}^{\mathbb{Z}, c}$} & Color \\
\hline $\begin{array}{l}7 \mathrm{a} \\
7 \mathrm{~b} \\
7 \mathrm{c} \\
7 \mathrm{~d}\end{array}$ & $\begin{array}{l}\text { PAI8a } \\
\text { PAI8b } \\
\text { PAI8c } \\
\text { PAI8d }\end{array}$ & $\begin{array}{l}90 \\
92 \\
85 \\
88\end{array}$ & $\begin{array}{l}0.45 \\
0.45 \\
0.48 \\
0.42\end{array}$ & $\begin{array}{l}-35.12 \\
-35.84 \\
-36.20 \\
-28.75\end{array}$ & $\begin{array}{l}-18.45 \\
-25.16 \\
-27.93 \\
-16.77\end{array}$ & $\begin{array}{l}\text { Orange } \\
\text { Orange } \\
\text { Orange } \\
\text { Orange }\end{array}$ \\
\hline $\begin{array}{l}{ }^{\text {aPolymers }} \\
{ }^{\mathrm{b}} \text { Measured } \\
{ }^{\mathrm{c}} \text { Measured }\end{array}$ & $\begin{array}{l}\text { cipitated } \\
\text { entration } \\
\text { filter. }\end{array}$ & $\mathrm{dL}^{-1}$ in $\mathrm{DI}$ & $25^{\circ} \mathrm{C}$ & & & \\
\hline
\end{tabular}

\section{Polymer characterization}

The FTIR spectra of all polymers showed absorptions around 1717$1777 \mathrm{~cm}^{-1}$, commonly attributed to the asymmetric and symmetric stretches of carbonyl groups. The presence of imide heterocycle in these polymers was revealed by absorption around 1376 and $725 \mathrm{~cm}^{-1}$ which belong to carbonyl bendings of imide. Bands of amide $\mathrm{N}-\mathrm{H}$ and hydroxyl groups appeared at around $3370-3416 \mathrm{~cm}^{-1}$. A representative FTIR spectrum for PAI8b is illustrated in Figure 1. Some of the polymers structures were also confirmed with ${ }^{1} \mathrm{H}$ NMR spectroscopy. Figure 2 shows the ${ }^{1} \mathrm{H}$ NMR $(400 \mathrm{MHz})$ spectrum of PAI8b. In the ${ }^{1} \mathrm{H}$ NMR spectrum of this polymer, appearances of the N-H protons of amide groups at $8.76,10.78,10.85 \mathrm{ppm}$, as three singlet peaks, and $\mathrm{OH}$ groups at 10.15 and $10.23 \mathrm{ppm}$ as two singlet peaks, respectively, indicate the presence of amide groups in the polymer's side chain as well as main chain and hydroxyl groups in the polymer's side chain. The resonance of aromatic protons appeared in the range of $6.45-8.53 \mathrm{ppm}$. The proton of the chiral center appeared as doublet at $4.63-4.65 \mathrm{ppm}$.

\section{Solubility of PAIs}

There is an assembly of general rules for polymer solubility, based on experimental observations, from which interesting conclusions can be obtained. It is well known that the dissolution of polymers depends not only on their physical properties, but also on their chemical structure, such as polarity, molecular weight, branching, crosslinking degree, and crystallinity. Thus, the introduction of flexible linkages and polar functional groups into the main chain or the side chain of aromatic polymers greatly enhances molecular mobility and provides better solubility. So, in the case of these polymers, the introduction of bulky groups as well as hydroxyl functional groups in the polymer side chain can improve the solubility. The solubility of obtained PAIs (8a-8d) was investigated as $0.01 \mathrm{~g}$ of polymeric sample in $2 \mathrm{~mL}$ solvent. All of the polymers are soluble in organic solvents such as DMF, DMAc, DMSO, NMP, pyridine, and in $\mathrm{H}_{2} \mathrm{SO}_{4}$ at room temperature and phenolic solvents such as m-cresol, and are insoluble in solvents such as methanol, ethanol, chloroform, methylene chloride, and water (Table 2). 


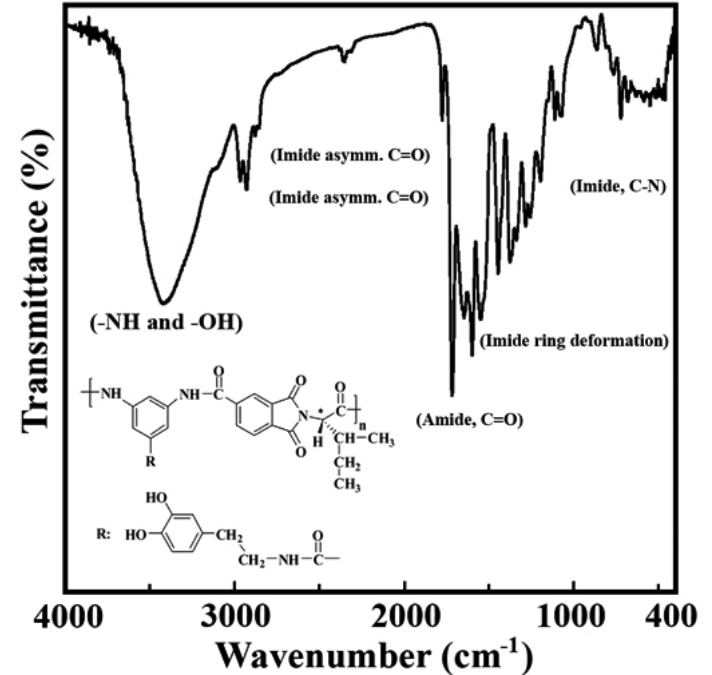

Figure 1. FTIR spectrum of PAI8b.

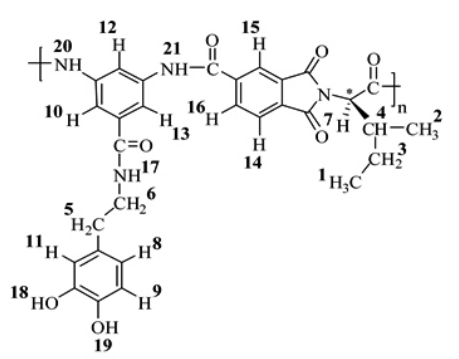
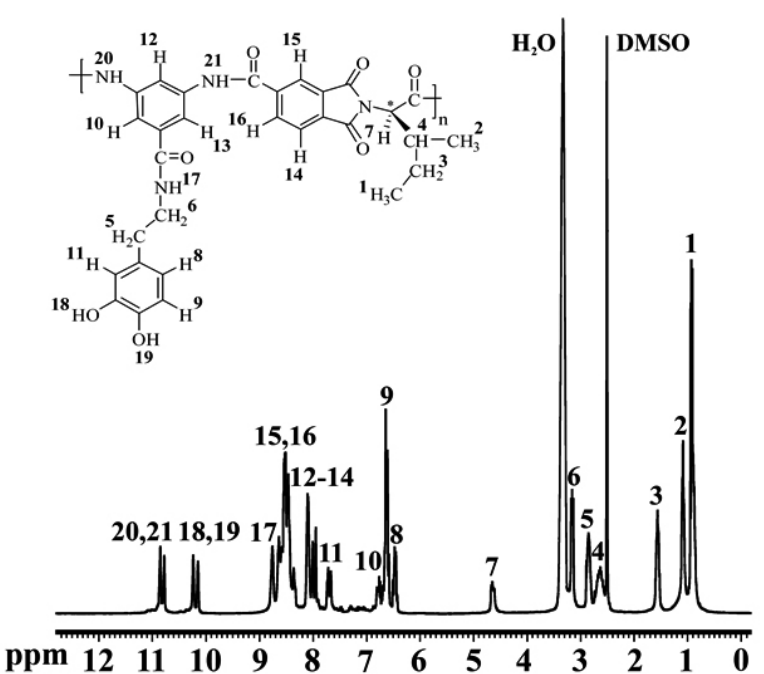

Figure 2. ${ }^{1} \mathrm{H}$ NMR $(400 \mathrm{MHz})$ spectrum of PAI8b in DMSO- $d_{6}$ at RT.

\begin{tabular}{|c|c|c|c|c|}
\hline \multirow{2}{*}{ Table 2: Solubility of PAIs 8a-8d ${ }^{\mathrm{a}}$. } \\
\hline \multirow{2}{*}{ Solvent } & \multicolumn{5}{|c|}{ Polymer } \\
\cline { 2 - 5 } & $8 \mathrm{a}$ & $8 \mathrm{~b}$ & $8 \mathrm{c}$ & $8 \mathrm{~d}$ \\
\hline DMAc & + & + & + & + \\
\hline DMF & + & + & + & + \\
\hline DMSO & + & + & + & + \\
\hline NMP & + & + & + & + \\
\hline Pyridine & + & + & + & + \\
\hline $\mathrm{H}_{2} \mathrm{SO}$ & + & + & + & + \\
\hline $\mathrm{CH}_{3} \mathrm{OH}$ & - & - & - & - \\
\hline $\mathrm{C}_{2} \mathrm{H}_{5} \mathrm{OH}$ & - & - & - & - \\
\hline $\mathrm{CHCl}_{3}$ & - & - & - & - \\
\hline $\mathrm{CH}_{2} \mathrm{Cl}_{2}$ & - & - & - & - \\
\hline $\mathrm{H}_{2} \mathrm{O}$ & - & - & - & - \\
\hline $\mathrm{a}(+) \mathrm{Soluble}_{2}$ in room temperature, $(-)$ Insoluble in room temperature. \\
\hline
\end{tabular}

Thermal properties

The thermal properties of two PAIs (8b) and (8c) were examined by TGA and derivative of thermaogravimetric (DTG) in a nitrogen atmosphere at a heating rate of $20^{\circ} \mathrm{C} / \mathrm{min}$. Typical TGA curves of representative PAIs $8 \mathrm{~b}$ and $8 \mathrm{c}$ in nitrogen atmospheres are shown in Figure 3. The thermal stability of the polymers was studied on the basis of 5 and $10 \%$ weight losses $\left(\mathrm{T}_{5}\right.$ and $\mathrm{T}_{10}$, respectively) of the polymers and the residue at $800^{\circ} \mathrm{C}$. These polymers exhibit good resistance to thermal decomposition, upto $290^{\circ} \mathrm{C}$ in nitrogen, and began to decompose gradually above that temperature. $\mathrm{T}_{5}$ for these polymers ranged from 293 to $325^{\circ} \mathrm{C}$ and the $10 \%$ weight loss temperatures of these polymers in nitrogen were recorded in the range of $315-350^{\circ} \mathrm{C}$. The concentration of carbonized residue (char yield) of these polymers in a nitrogen atmosphere was more than $40 \%$ at $800^{\circ} \mathrm{C}$. The high char yields of these polymers can be ascribed to their high aromatic content. The char yield can be applied as a decisive factor for estimated the limiting oxygen index (LOI) of polymers according to Van Krevelen and Hoftyzer equation [40]:

$$
\mathrm{LOI}=17.5+0.4 \mathrm{CR} \quad(\text { Where } \mathrm{CR}=\text { Char yield })
$$

PAIs $8 \mathrm{~b}$ and $8 \mathrm{c}$ had LOI values around 35 , which were calculated from their char yield. A polymer having LOI more than 28 is considered as effective flame retardant.

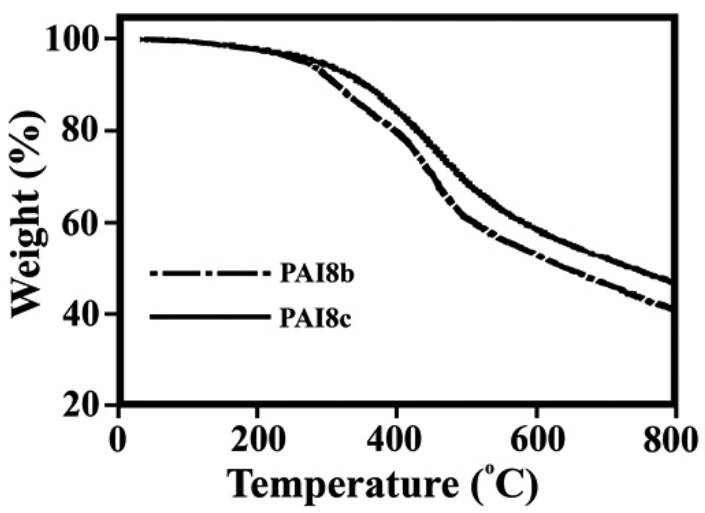

Figure 3. TGA curves of PAI8b and PAI8c (in nitrogen at a heating rate of $20^{\circ} \mathrm{C} / \mathrm{min}$ )

\section{XRD analysis}

As indicated by X-ray diffractograms of PAIs ( $8 \mathrm{~b}$ and $8 \mathrm{c}$ ) in Figure 4 , the weak reflection centered at a $2 \theta$ value around $20^{\circ}$ was characteristic of the amorphous polymers. This might have been caused by the presence of heterocyclic imide groups and aromatic structures in the polymer chain which limit the molecular mobility of all the polymers and constrict the formation of crystals.

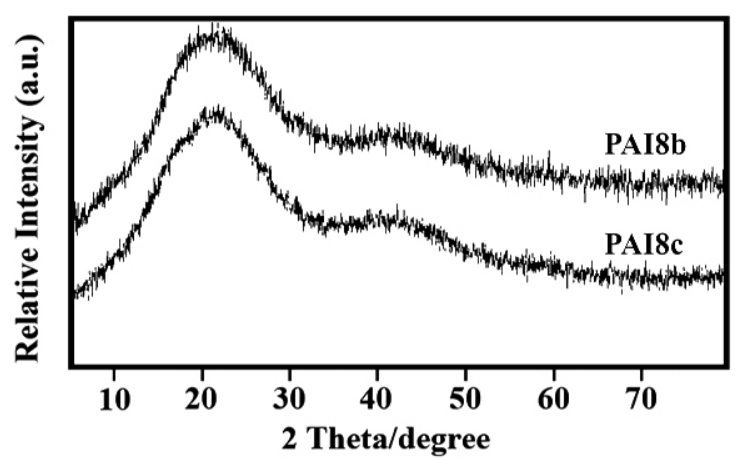

Figure 4. XRD patterns of PAI8b and PAI8c

Morphological studies

Morphological characterization of PAIs was studied by FE-SEM. Shown in Figure 5 are the respective FE-SEM images of PAI8b and PAI8c. As can be seen from these images, the average diameter of polymeric particles is in the range of $46-54 \mathrm{~nm}$ and shape of them is spherical. 
It is well known that ultrasounic irradiation is a well-established method for particle size reduction in dispersions and emulsions as well as generation and application of nano-size materials, because of the potential in the deagglomeration and the reduction of primaries. As most nanomaterials are still fairly expensive, this aspect is of high importance for the commercialization of product formulations containing nanomaterials [41]. Herein, powders of polymers have been subjected to irradiation with high-intensity ultrasound for one hour while suspended in ethanol. The homogeneous suspension was placed in a $60^{\circ} \mathrm{C}$ oven overnight to evaporate most of the solvent. Then the semidried polymer powder was further dried in vacuo at $80^{\circ} \mathrm{C}$ for $8 \mathrm{~h}$. The resulting images from FE-SEM confirmed that after ultrasonic irradiation the size of polymeric nanoparticles was decreased (39-50 nm) (Figure 6).
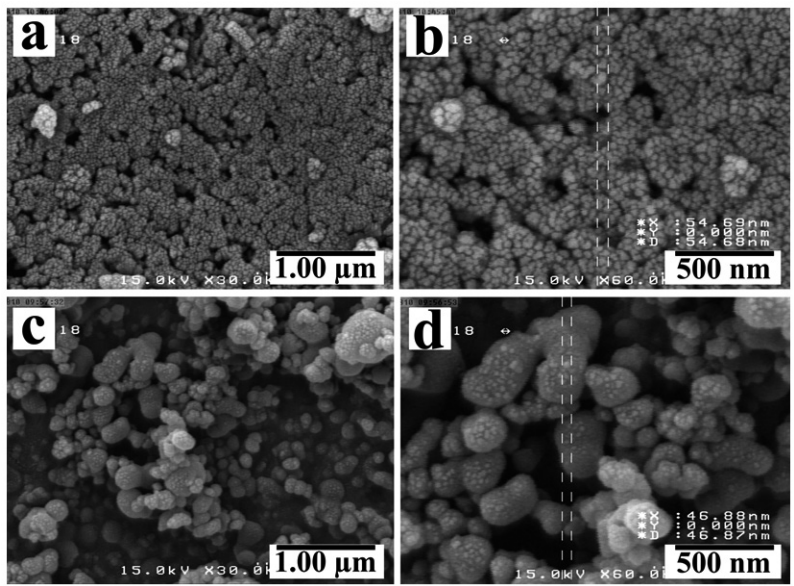

Figure 5. FE-SEM micrographs of PAI8b ( $a$ and b) and PAI8c (c and d)

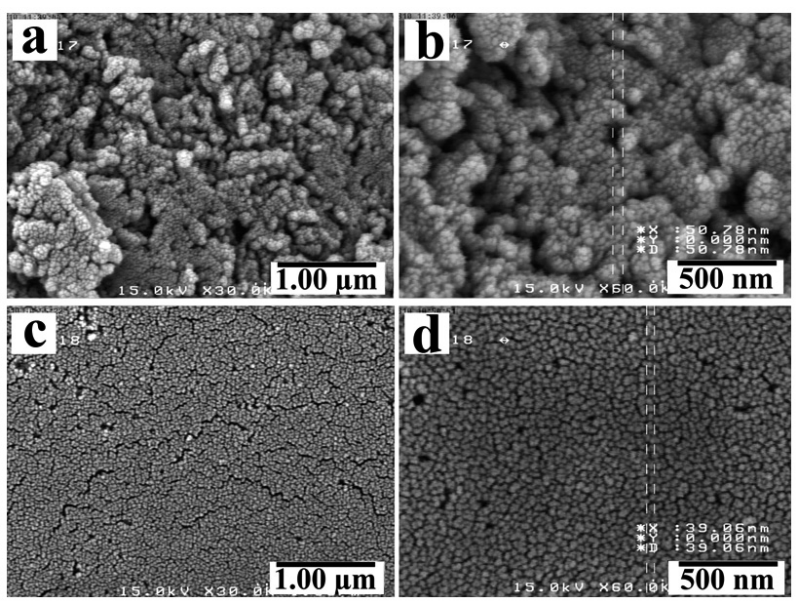

Figure 6. FE-SEM micrographs of PAI8b ( $a$ and b) and PAI8c (c and d) after sonication process

\section{CONCLUSIONS}

This work involved the syntheses of several new optically active, thermally stable and nanostructured PAIs having pendant dopamine moiety by direct polycondensation reaction of various chiral diacids with a synthesized aromatic diamine in molten TBAB as an efficient medium. The introduction of flexible linkage with several functional groups into the main chain or side chain of these aromatic polymers greatly enhanced molecular mobility and provided better solubility. As a result of the outstanding thermal properties, these chiral PAIs have a widely applied prospect in high-powered materials, processable high-performance engineering plastics, constructing chiral media for asymmetric synthesis, chiral stationary phases for resolution of racemic mixtures by chromatographic techniques. Futhermore, the $\mathrm{OH}$ groups of the obtained PAIs can readily be reacted with difunctional acids or diisocyanates to form crosslinked materials for future applications.

\section{ACKNOWLEDGEMENT}

We are grateful to the Research Affairs Division Isfahan University of Technology (IUT), National Elite Foundation (NEF), and Center of Excellency in Sensors and Green Chemistry Research (IUT) for the financial support.

\section{REFERENCES}

1.- $\quad$ G. Wilde Nanostructured Materials, Elsevier, 2009.

2.- H.S. Nalwa ed. Polymeric Nanostructures and Their Applications, American Scientific Publishers, 2007.

3.- Y. Xia, J.A. Rogers, K.E. Paul, G.M. Whitesides, Chem. Rev. 99, 1823, (1999)

4.- $\quad$ L. Huang, Z. Peng, G. Guo, A.L. Porter, J. Bus. Chem. 7, 15, (2010)

5.- M.N.V.R. Kumar, M. Sameti, C. Kneuer, A. Lamprecht, C.M. Lehr in Polymeric Nanoparticles for Drug and Gene Delivery, H.S. Nalwa ed. Encyclopedia of Nanoscience and Nanothechnology, Volume 9, pp. 1-19.

6.- V.H.C. Requena, K. Bouchemal, C. Vauthier, G. Ponchel, J. Chil. Chem. Soc. 53, 1677, (2008)

7.- $\quad$ M. Muccini, M. Murgia, F. Biscarini, Adv. Mater. 13, 355, (2001)

8.- H. Biederman, Vacuum 59, 594, (2000)

9.- $\quad$ R. Maurer, J. Mater. Sci. 27, 6279, (1992)

10.- K.L. Mittal Polyimides and Other High Temperature Polymers, Volume 2, Utrecht, Boston, 2003.

11.- D.J. Liaw, C.C. Huang, W.H. Chen, Polymer 47, 2337, (2006)

12.- S.H. Hsiao, G.S. Liou, Y.C. Kung, Y.J. Lee, Eur. Polym. J. 46, 1355, (2010)

13.- L.H. Tagle, C.A. Terraza, H. Villagra, A. Tundidor-Camba, Polym. Bull. 67, 1799, (2011)

14.- I. Bacosca, E. Hamciuc, M. Bruma, M. Ignat, React. Funct. Polym. 71, 905, (2011)

15.- A. Kausar, S. Zulfiqar, Z. Ahmad, M.I. Sarwar, Polym. Degrad. Stab. 95, 2611, (2010)

16.- X. Ma, N.H. Lee, H.J. Oh, J. S. Hwang, S.J. Kim, Nanoscale Res. Lett. 5, 1846, (2010)

17.- S. Rajesh, P. Maheswari, S. Senthilkumar, A. Jayalakshmi, D. Mohan, Chem. Eng. J. 171, 33, (2011)

18.- T.J. Murray, Macromol. Mater. Eng. 293, 350, (2008)

19.- W.M. Nelson, Green Solvents for Chemistry: Perspectives and Practice (Green Chemistry Series), Oxford University Press, USA, 1 edition, 2003.

20.- B. Kirchner, B. Clare Ionic Liquids, Springer, 2010.

21.- J. Dupont, R.F. de Souza, P.A.Z. Suarez, Chem. Rev. 102, 3667, (2002)

22.- H. Zhao, S. Xia, P. Ma, J. Chem. Technol. Biotechnol. 80, 1089, (2005)

23.- J. Zheng, S.S. Moganty, P.C. Goonetilleke, R.E. Baltus, D. Roy, J. Phys. Chem. C 115, 7527, (2011)

24.- S. Mallakpour, Z. Rafiee, Prog. Polym. Sci. 36, 1754, (2011)

25.- B.C. Ranu, A. Das, S. Samanta, J. Chem. Soc., Perkin Trans. 1 1520, (2002)

26.- V. Calo, A. Nacci, A. Monopoli, A. Damascelli, E. Ieva, N. Cioffi, J. Organomet. Chem. 692, 4397, (2007)

27.- X. Sun, J. King, J.L. Anthony, Chem. Eng. J. 147, 2, (2009)

28.- L. Nagarapu, V.N. Cheemalapati, S. Karnakanti, R. Bantu, Synthesis 19, 3374, (2010)

29.- S. Mallakpour, Z. Rafiee, Polymer 48, 5530, (2007)

30.- S. Mallakpour, Z. Rafiee, Eur. Polym. J. 43, 1510, (2007)

31.- S. Mallakpour, A. Zadehnazari, High Perform. Polym. 22, 567, (2010)

32.- A. Berthod ed. Chiral Recognition in Separation Methods. Mechanisms and Applications, Springer, Verlag Berlin Heidelberg, 2010.

33.- I. Ojima Catalytic Asymmetric Synthesis, John Wiley and Sons, 2010.

34.- S. Mallakpour, A. Zadehnazari, Express Polym. Lett. 5, 142 (2011)

35.- S. Mallakpour, M. Hatami, A.A. Ensafi, H. Karimi-Maleh, Chin. Chem. Lett. 22, 185, (2011)

36.- A. Staubli, E. Ron, R. Langer, J. Am. Chem. Soc. 112, 4419, (1990)

37.- S. Mallakpour, A.R. Hajipour, M.H. Shahmohammadi, J. Appl. Polym. Chem. 89, 116, (2003)

38.- S. Mallakpour, A.R. Hajipour, M.H. Shahmohammadi, Iran. Polym. J. 11, 425, (2002)

39.- S. Mallakpour, A.R. Hajipour, S. Habibi, J. Appl. Polym. Chem. 80, 1312 , (2001)

40.- D.W. Van Krevelen, Polymer 16, 615, (1975)

41.- T.J. Mason, J.P. Lorimer Applied Sonochemistry: Uses of Power Ultrasound in Chemistry and Processing, Wiley-VCH Verlag GmbH \& Co. KGaA, 2002. 